\title{
The Forms of Representation in Architectural Design Teaching: The cases of AUIC-POLIMI and FAUP
}

XXIV International Conference of the Iberoamerican Society of Digital Graphics Medellin | Colombia

\author{
Rafael Sousa Santos \\ Faculty of Architecture, University of Porto | Portugal | rfl.ss.santos@gmail.com \\ Clara Pimenta do Vale \\ Faculty of Architecture, University of Porto | Portugal | clara_vale@arq.up.pt \\ Barbara Bogoni \\ School of Architecture Urban Planning Construction Engineering, Politecnico di Milano | Italy \\ | barbara.bogoni@polimi.it
}

Poul Henning Kirkegaard

Department of Engineering, Aarhus University | Denmark | phk@eng.au.dk

\begin{abstract}
This paper presents the results of a research developed on the following problem: the relation between forms of representation and the architectural design teaching. The research had as its study object the Design Educational Model of two architecture schools: AUIC-POLIMI and FAUP. The objective of the research described in this paper was to characterize the didactic approach to design of both schools, focusing on the representative component and its role in design teaching.
\end{abstract}

Keywords: Architectural Design Teaching; Architectural Education; Design Critiques; Design Studio; Forms of Representation.

\section{INTRODUCTION}

Design occupies a central position in architectural practice and education. Often understood as a problem-solving process, design appears to be primarily a problem setting process. The complexity of the procedures necessary to achieve this double process requires the designer to use external representations as a cognitive support. These external representations, in addition to their importance as a design instrument, also assume a determining role in the educational context, functioning as a means of interaction between professors and students in design studios.

With this paper it is intended to present the results of a research developed on the relation between forms of representation and the architectural design teaching. The research had as its study object the Design Educational Model (DEM) of two architecture schools - the School of Architecture Urban Planning Construction Engineering of the Politecnico di Milano (AUIC-POLIMI) and Faculty of Architecture of the University of Porto (FAUP). The objective of the research described in this paper was to characterize the didactic approach to design of both schools, focusing on the representative component and its role in design teaching.

The results presented in this paper correspond to AUICPOLIMI case and are organized into three themes: curricular context, organization of design studios, and design critiques approach. In the discussion section, these results are compared with the FAUP case following the same themes and are analysed based on the literature. In the final part, the aspects that characterize the DEM of the two schools are summarized.

\section{BACKGROUND}

\subsection{DESIGN AND REPRESENTATION}

Self and Goldschmidt (2018) define architectural design as the process of transforming an existing situation into a preferential one. As Nelson and Stolterman (2012) refer, the designer's purpose is not to identify a universal truth or "the right solution", but rather the most appropriate alternative for an existing situation. In this sense, Goldschmidt (1991) proposes an understanding of design, not only as a problem solving process, but also as a problem setting process. These two fundamental procedures of the design process can be understood as follows: problem setting as recognition - through perception and analysis - and problem solving as transformation of the world - through synthesis (Have \& Toorn, 2012).

Whether as recognition or transformation, the entity to which the designer reacts is made up of physical properties - mostly complex sets of properties - and cannot therefore be resolved only in the abstract or mental dimension (Self \& Goldschmidt, 2018). Thus, both in the attempt to formulate the problem and in the search for potential solutions, the designer needs to resort to external representations (Goldschmidt, 1991).

Visser (2006) propose a definition for the designer's activity as the construction of representations, external and internal, individual or shared, where the modalities are verbal, graphic or gestural. In line with this idea, Milovanovic (2019) highlights that the design process is developed in the interaction between external and internal or mental representations. However, it is important to consider that the relationship between external and internal 
representations is not univocal, that is, an external representation is not the externalization of a pre-conceived idea in the designer's mind. As Goldschmidt (1991) argues, the production of external representations is itself part of the cognitive projection process: the designer thinks through representation.

There seem to be two major aspects to consider in the relationship between the designer and the external representations from a cognitive point of view. First, as Goldschmidt (2017) refers, the designer establishes a dialogue with the representations produced - this perspective is also compatible with Schön's (1992) proposal of designing as a "reflexive conversation". Working as visual devices, the generated representations "talk-back", returning information that the designer did not put there intentionally or consciously - as Milovanovic (2019) refers, answering questions that were not even asked. Second, as defended by Herbert (1988), the emergence of discoveries also occurs in the physical act of representing itself - when trying to express internal representations the designer is forced to build a specific organization of the elements.

As a cognitive support, Purcell and Gero (1998) underline the importance of less structured forms of representation in particular free hand drawing or sketching - distinguishing them from the more structured forms of representation such as technical representations, produced by hand or digitally. This idea is frequently formulated as "sketching is a cognitive instrument" or simply "sketching is thinking" (Goldschmidt, 1989, 1991, 2014, 2017; Herbert, 1988; Milovanovic, 2019; Milovanovic \& Gero, 2020; Purcell \& Gero, 1998; Tversky \& Suwa, 2009; Williams \& SanchezDel-Valle, 2008).

But what are the characteristics of these less structured forms of representation, such as sketching, that guarantee their effectiveness as an instrument to support design? According to Goldschmidt (1991), especially in the conceptual phases, the form of representation chosen must allow the design process - that is, the interaction between internal and external representations (Milovanovic, 2019) to be fluid and uninterrupted. In this sense, Goldschmidt (1991) states five characteristics of a form of representation that can be considered qualities in the design process: speed of production, minimal generation rules, tolerance to ambiguity, inaccuracy and incompletion, transformability and reversibility, and flexible stop-rules. Sketching seems to be the form of representation that brings together most of these characteristics (Goldschmidt, 1991).

Considering the qualities of skeching, Tversky and Suwa (2009) also underline the speed of production - when compared to other forms of representation, such as the modeling -, the requirement of few cognitive resources or generation rules, as well as ambiguity - ambiguity in sketches, instead of promoting confusion, they promote innovation (Tversky and Suwa, 2009). To these characteristics-qualities, Tversky and Suwa (2009) also add the possibility of focusing on some aspects without losing the general sense, the possibility of exaggerating, emphasizing or distorting aspects or elements of the design, thus the possibility of acquiring a public nature, even when fulfilling an initial private purpose.

\subsection{DESIGN TEACHING AND LEARNING}

Design also occupies a central position in architectural education. The purpose of the design studio in the architecture course is that the student learns to design, as stated by Gero and Milovanovic (2020), developing skills in the interpretation of problems and in the evaluation of design solutions. The general understanding that appears in the literature is that the student learns to design by doing, that is, by carrying out an architectural design (Milovanovic, 2019; Schön, 1983; Visser, 2006).

Schön (1983) defines the design studio didactics as a process of individual and collective learning by doing, influenced, and guided by the feedback of a practitioner. Thus, what happens in the design studio is a kind of simulation of professional practice in an architecture studio or atelier - the professor can be seen as the project manager, the class as co-workers, the exercise brief as an order for a real design. In fact, the realistic dimension of design is an important aspect in an educational context (Milovanovic, 2019).

The particularity of the design studio is perhaps that the study object - i.e. the design itself - cannot really be taught. Thus, the students have a fundamental role in the construction of their own learning, asserting themselves as a subject and not the object of teaching (Alves Costa, 1991). As Schön (1983) argues, learning to design comes as the synthesis of a global experience, where students need to give meaning to their design experience - that is, assign a pedagogical meaning to their activity in the design studio. This idea is in line with Ortega y Gasset (1983), who argues that the students need to recognize the immediate need for the knowledge that comes to them in order to really assimilate it.

During the "controlled self-training" path of the architecture student, the professor assumes the role of a tutor or advisor (Milovanovic, 2019). The professor's role as a tutor, more than helping the student to carry out the exercise and reach a result, involves encouraging him to reflect on his work (Milovanovic, 2019).

\subsection{DESIGN CRITIQUES AND REPRESENTATION}

Design critiques or reviews correspond to the key moment of the interaction between professors and students in design studios (Oh, Ishizaki, Gross, \& Yi-Luen Do, 2103). Through design critiques, students receive important feedback about the development of their designs. Theses critiques can take many formats: one-on-one desk critiques involving a professor and a student, group reviews, peer discussions, pin-ups, and juries (Milovanovic, 2019; Oh et al., 2013)

Oh et al. (2013) also observed a sequential organization of critiques that can be summarized in the following steps: students present their work, professors listen and observe, and often they point out potential problems that lead to an open discussion on these themes. Goldschmidt et al. (2010) propose the organization of professors' critiques in eight categories: an analysis of the state of design; clarification issues; a proposal for change or improvement; a previous design reference; an explanation of design issues, a theory, a principle, a norm; statements regarding representation or methodology; an encouragement; and identifying a project error. As important fact, as Gero and 
Milovanovic (2020) refer, is that about $60 \%$ of professors' verbalizations during design critiques are followed up with an action in external representations.

However, for the critiques to acquire pedagogical quality, some aspects must be considered (Milovanovic, 2019). On the one hand, professors need to build constructive criticism and be clear about their objectives. This is important for the student, so that he does not understand the critique as a mere personal opinion - so, fundamentally subjective - or a personal judgment, but as the vision of an experienced professional (Milovanovic, 2019). On the other hand, as Schön (1987) argues, professors must encourage students to accept the experimental aspect of the exercises in the design studio, to avoid them being stuck at the risk of failing. Students who take a defensive stance in the design studio tend to be limited in design experimentation, and consequently in possible pedagogical contributions.

In the educational context, the role of representation also acquires a new complexity and importance. As Milovanovic (2019) argues, the set of external representations produced by the student "is a key element in the pedagogical situation of design critiques": the interaction between professors and students is channelled through the representations used during the design critiques (Milovanovic, 2019).

What happens is that the student's external representations, in addition to serving as a means of design (of thinking), also serve as a record of the mental-path taken, as a means of communication with the professor, and above all as a support for discussion and collaboration between them - as a "trading platform", which Milovanovic (2019) refers to as the "representational ecosystem". The concept of "representational ecosystem" is proposed by Dorta, Kinayoglu, and Boudhraa (2016) as the set of produced external representations - sketches, diagrams, plans, sections, mock-ups, digital models, simulations and animations of the design object - and their inter relationships, functioning as an "environment for the interaction" between the student and the professor (Milovanovic, 2019).

\section{METHODOLOGY}

The research that produced the results presented here was developed according to a qualitative embedded single case study, as described by Robert Yin (1984) - in fact, case study strategies have been frequently adopted in educational researches (Merriam, 1998; Stake, 1995; Yin, 1984). Taking as a case study the School of Architecture Urban Planning Construction Engineering of the Politecnico di Milano (AUIC-POLIMI), it was intended to approach the study object - i.e. the Design Educational Model (DEM) - through three embedded unities of analysis: the educational Purposes, Principles and Practices.

In view of the ontological-epistemological impossibility of fully understanding the phenomenon (Yin, 2011) the approach was based on the "multiplication of points of view", that is, through multi-methods for data collecting and recording and multi-sources of evidence (Creswell, 1994; Manion, Cohen, \& Morrison, 1980). Moreover, as mentioned in the literature (Manion, Cohen, \& Morrison,
1980), it was necessary to guarantee the explicit linking of the evidence with the study.

Thus, in order to guide the procedures of data collecting, recording, analysing, and interpreting a Case Characterization Matrix (CCM) was formulated. The CCM allowed to relate the three embedded unities of analysis the educational Purposes, Principles and Practices - with the three main sources of evidence in which the object of study manifests itself: the professors, expressing how the model is Assumed; the architectural design classes, expressing how the model is Achieved; and the students, expressing how the model is Acquired.

The main research methods used were naturalistic observation, participatory observation, in-person-interview, and conversation - individual or group - complemented with artifact analysis, and documentary and bibliographic review. Due to the exploratory character that was intended in this approach to the case study, an open data collection model was followed (Yin, 1984). The collected field data was recorded in raw field notes (Hatch, 2002), then transcribed and organized into the so-called Didactic Registration Units (DRU). Thematic analysis method was used to treat the collected data (Creswell, 1994; Salkind, 2010).

The case study approach took place between November 2019 and February 2020, and two courses were considered: the Bachelor Program in Architectural (POLIMI, 2019b) and the Master Program in Architectural Design and History (POLIMI, 2019a). During this period, all design studio classes from the first semester were attended, namely Laboratorio di Progettazione Architettonica 1, 2 and 3, Laboratorio di Progettazione dell'Architettura degli Interni, Architectural Design Studio and Planning in Historical Context Studio. It was sought that the observation of the design studios could happen during different moments of the didactic, such as design critiques or review classes, deliveries, exercises presentations and moments of evaluation.

\section{RESULTS}

\subsection{CURRICULAR CONTEXT}

There are some curricular differences related to design studios between the Bachelor and the Master Program taught at AUIC-POLIMI. In the Bachelor Program, the design studios of the first and second years are annual courses, while in the third year a semi-annual regime is followed. During the three years of the Bachelor, the didactic contents or syllabus are defined individually by the professors of each studio. In the Master Program, all design studios are semi-annual and, unlike what happens in the Bachelor Program, there is a general planning of the syllabus to be addressed in the different design studios.

On the other hand, the courses that directly address the representative component in the Bachelor Program are: the semi-annual course Fondamenti della Rappresentazione; a module of Laboratorio di Progettazione 1 called Tecniche della Rappresentazione; and the semi-annual course Tecniche di Rilievo and Modellazione 3D per I 'Architettura. In the Master Program: the semi-annual course Survey Advanced Techniques; and the optative semi-annual course Tecniche di Rappresentazione dello Spazio. 


\subsection{ORGANIZATION OF DESIGN STUDIOS}

Design studios are mostly organized in one of two ways: a single exercise brief with several phases, or a multiple exercise (two or three) brief with several phases. In turn, most exercises are aimed at groups of three or five students. The nature of these exercises can be analytical or synthetic. Often analytical and synthetic approaches appear interspersed on exercises or phases - however, in some studios only analytical exercises are proposed. The context of the synthesis exercises also varies: a design with a real site, a design with an imagined site or a design without a site.

In the case of the design studios of the Master Program in Architectural Design and History, all the synthesis exercises are located in the Municipality of Mantova - the use of the city itself as a field of study is one of the assumptions of this Master Program (POLIMI, 2019a). The degree of involvement with reality also varies between design studios: some professors take students to real situations, making them interact with urban agents, technicians, or the population.

A constant in AUIC-POLIMI is the fact that the briefs of the synthesis exercises refer to the general plan of the design, the objectives and elements required for the evaluation, but not the detailed program with functions and areas: it is up to the students to study designs with a similar program and make a proposal themselves - in a form of precedent analysis. During design studios, students have several moments of presentation-evaluation. The most required elements are panels - with images, photographs, technical representations, and schemes - models and portfolios. At the end there is a final presentation-evaluation moment called prova d'esame or final exame. The presentation model is similar, but involves a jury made up of professors and guests.

\subsection{DESIGN CRITIQUES APPROACH}

Several critical design setups are possible: one-on-one review at the student's desk; one-on-one review at the "professor's desk"; collective review around one or more large tables. In design critiques, the professor interacts with the student verbally, gesture and through external representations. The form of representation that is always used by professors is freehand drawing or sketching, as contour or line drawings: quick perspectives, sections, plans, and diagrams.

These representations are made with a pencil, pen or marker on the students' external representations, on a sheet of tracing paper placed on top of the originals, on a loose sheet or on personal notebooks. During design critiques, in addition to discussing the content of students' work, professors often discuss how to represent and communicate the exercise results - this is in fact a very recurrent topic during critiques. Often professors encourage continuity in the students' work, helping them to develop a general coherence of their designs: as the resolution of its internal conflicts or the disclosure of its strengths.

In turn, it is rare for students to use sketching during revisions as an arguing means. Sketching is neither widely used nor given special importance in relation to other forms of representation between students. However, despite the lack of training and experience, in certain situations students can express themselves more easily and effectively with a quick sketch. Students seem to have complete freedom in terms of representation forms: they mostly work with CAD software, with image production and editing software, and many already use BIM software. The type of representation that appears to be a constant is the axonometric projection in line, usually made in CAD or extracted from a 3D or BIM model. The only representative restrictions come from the personal initiative of some professors - for example, in the first-year design studio, students are asked not to use the computer in the early stages of work.

It is not usual for students to bring study or private representations to the design critiques, elaborated during the design process, but presentation or public representations conceived precisely for that purpose - as images, rigorous representations, or diagrams. There is an expressive investment by students in the final elements for presentation-evaluation - especially in panels and portfolios - but also the way they present it - the discourse, gesture and even the way they dress.

The technical representations usually have a stylized character (abstracted or thematic), similar to a competitiontype representation. This way of representing, although it works well in communicating the general configuration and its design intentions, does not effectively transmit the constructive dimension. The way most students design seems to take little advantage of representation: most do not seem to actively use representation as a cognitive instrument to support design. Instead of the idea of thinking through representation, it seems that students tend to think first and then represent. This method or way of working by students seems to be related to a general difficulty in design exploration

\section{DISCUSSION}

\subsection{CONTEXT AND ORGANIZATION IN BOTH SCHOOLS}

Between AUIC-POLIMI and FAUP there is a first difference related to the curricular configuration. While at AUICPOLIMI a Bachelor Program (three years) and a Master Program (two years) are taught, at FAUP there is only one Integrated Master Program (five years). All FAUP design studios are annual, and there is a general planning of the syllabus for the five years. At FAUP there is a direct link between design studios and some courses - such as the annual courses of Desenho, Construção and Sistemas Estruturais - both from the content and evaluation point of view. In these courses, the object of study is the design being developed by the student in design studio.

This strategy of disciplinary interrelationship seems to be an asset for the student, both for deepening and developing the design, as well as for the positive involvement that is necessarily created in these courses. At FAUP there is also a significant curricular presence of the representative component, namely in the annual courses of Desenho I and Geometria in the first year, in the annual course of Desenho $I I$ in the second year, in all five optional semi-annual courses in the third year, and in three optative semi-annual courses in the fourth and fifth year. 
In general, the two schools follow the same organization in design studios. Also at FAUP, the single exercise brief with several phases and multiple exercise brief with several phases are usual. There are, however, some differences to note. A first difference is that in AUIC-POLIMI the exercises in the design studio are mostly directed to groups, while in FAUP there is a strong component of individual work. It is possible to recognize positive and negative aspects in each of the pedagogical strategies.

The focus on group work, as at AUIC-POLIMI, leads students to develop the ability to work in a collaborative design model, which seems to be an important dimension in professional practise. However, it can pose difficulties for their individual development: passing most of the phases of group work - because students tend to dedicate themselves to tasks that they master best - they can reach the end of the course without having experienced all stages of an architectural design.

Another difference is the importance given to analytical exercises in the design studio at AUIC-POLIMI, whether in the form of analyzing a site context, or in the form of precedent analysis (Have \& Toorn, 2012; Lyn \& Dulaney, 2009; Toorn \& Guney, 2011). The importance given to analysis as a recognition procedure seems to be a particularity of AUIC-POLIMI.

At FAUP, however, the analytical approach in design studios is less relevant, with full emphasis on synthesis exercises. In some cases, an analysis is required as the initial phase of an exercise. However, often the site context is recognized through a perceptive-intuitive approach and does not necessarily correspond to a work phase. This approach is related to the general purpose of the Master Program, in which students are trained in sketching, especially through visual drawing - as Mendes (in Portas, 1986) refers, through a "general training of drawing". In this way, learning to draw corresponds, among other things, to learning to see (Siza Vieira, 2009). The recognition of the site context or circumstance is then something related to the student's personal sensitivity (Távora, 1982), and is only relevant to the extent that it serves the design - so it does not correspond to an autonomous phase or exercise.

Moreover, there is always a site mentioned in FAUP's design studio exercises, whether real or imagined. Often the site mentioned in the exercises is real and can be visited by students. At FAUP there is a general understanding on the importance of the site for the design process - in cases where the student is stuck, it is common for the professor to recommend a new visit to the design site.

This perspective is expressed in the famous sentence by Siza Vieira (2000): "the idea is in site". According to Siza Vieria (in ESBAP, 1979), the synthesis procedure does not start from the information for the form but involves a form hypothesis from the first contact with the observed reality. The initial formulation of this form hypothesis or presolution, as Milovanovic (2019) refers, is a method normally used by experienced designers, and its purpose is to help reduce and frame the field of problem design.

In FAUP's design studios there are no precedent analysis exercises - this type of exercise is often accomplished in courses like Construção, Sistemas Estruturais, História da Arquitectura and Teoria da Arquitectura. Another difference are the exercise briefs: while at AUIC-POLIMI the definition of the program is up to the student - which partly justifies the importance of the precedent analysis -, at FAUP is always given the list of the types of spaces and minimal areas. This difference seems to be based on a matter of principle between the two educational models: at AUICPOLIMI the students need to research the programmatic aspects of the synthetical exercise, while at FAUP the importance is centred on the design process itself.

Although in both schools the moments of presentation and evaluation happen during the design studios they differ in final evaluation. The final exam, as at AUIC-POLIMI, does not exist at FAUP: the student delivers the final work but does not present it. Again, this difference can be explained by the understanding of each school about the objectives of the design studio: at AUIC-POLIMI, the communication of the results of the exercise - the direct communication of the student and his productions - is an important component of didactics, while in FAUP seems to be given more importance to the design elaboration and method.

\subsection{DESIGN CRITIQUES APPROACH IN BOTH SCHOOLS}

In both schools, professors argue with students using mostly sketching. The qualities of sketching as a form of representation - as enunciated by Goldschmidt (1991) and Tversky and Suwa (2009) - seem to continue to guarantee its importance in design critiques. As Williams and Sanchez-Del-Valle (2008) argues, digital forms of representation can compete with sketching at a presentation-communication level, but not necessarily as design-thinking medium.

The differences between the professors of the two schools lies, however, in the discussed content of design critiques. In addition to the discussions around the object of the students' work, at AUIC-POLIMI much importance is given to the way of representing and communicating the results. In turn, at FAUP is essentially discussed the design and a "more or less implicit" investment is made by the professors in design method. As Milovanovic (2019) argues, the content of professors' critiques is adjusted according to their pedagogical objectives - or educational Purposes -, which can be centred on several aspects, such as the process and concept development, the quality of communication and representation, or in innovation and creativity.

While at AUIC-POLIMI the content of the critiques promotes continuity and improvement of the students' design ideas - then focused on vertical deepening moves (Goldschmidt, 1989) -, at FAUP the critiques tend to promote exploration of ideas - then focused on horizontal moves (Goldschmidt, 1989), at least until the student finds "the right track". FAUP's approach leads the student to relativize the value of his work, making it easier to start over. Besides, also the resourcefulness in representation especially the drawing - seems to favour this exploration of design.

A significant difference in design critiques lies in the students of the two schools. On the one hand, FAUP students often use drawing in discussions with the 
professor - both argue through drawing. On the other hand, contrary to what happens at AUIC-POLIMI, the tendency is for students to bring study representations together with rigorous representations for design critiques. In fact, they are encouraged to do so by their professors. These two types of representation advance together, being used one and the other consecutively. The less structured forms of representation accompany the entire design process and are not necessarily limited to the initial-conceptual phases (Purcell \& Gero, 1998).

While at AUIC-POLIMI students have complete freedom in terms of forms of representation - with some specific exceptions - at FAUP students are prohibited from using the computer in the first two years of the course. During this period, students' productions should be limited to sketching, rigorous hand drawing and models. Although it seems an "old fashioned" rule, it is a strategy to countering a visible problem at AUIC-POLIMI: the great heterogeneity of first year students, with consequences for the following years.

This strategy of FAUP is supported by the curricular plan organization: in the first two years of the Integrated Master Program, students have several hours of training in sketching and geometry. This ensures that at least in terms of representative capabilities, all students are at a similar point, which in turn is a training close to their professors as stated by Távora (1991), drawing has been the school's continuity support, an expression of a unified thought about what should be the reflection and practice of architecture.

FAUP students make use of less structured forms of representation as sketching as an active instrument of designing, then, as a thinking medium (Goldschmidt, 1991). In this sense, many study or private representations are elaborated (Herbert, 1988) throughout the design process, serving these both to the students themselves and to design critiques.

These sketches are made by students on rigorous representations (mostly made in CAD), on trace paper, on separate sheets or in personal notebooks - the use of notebooks is common practice at FAUP, functioning as a kind of design diary (Have \& Toorn, 2012; Toorn, 2012). Most of the sketches made by the students are contour or line drawings, such as plans and sections, diagrams, but also some perspectives. It should be noted that although it is not so common, some students at AUIC-POLIMI also work in this way.

The representations produced by the students at FAUP as a study representation, - above all sketches - are often made quickly without much care with the "appearance", since the instrumental purpose prevails. Besides, the representations produced for presentation, namely for evaluation moments, are essentially rigorous representations for communicating to the "construction site", extolling the constructive dimension - favoured by the association of design studios with courses as Construção or Sistemas Estruturais.

Thus, there is an expressive investment in design, the details and clarification of its attributes in the rigorous representations, but the production of images is not so relevant as at AUIC-POLIMI. Although sketching is widely used by FAUP students in the design process, it is not normally used in the final presentation elements - as in the final panels. That is, sketching assumes a role as an instrument or means: its purpose is to support design and not to demonstrate personal virtuosity. As Purcell and Gero (1998) refer, it is an understanding of drawing as a design instrument and not as a personal skill.

\subsection{DESIGN EDUCATIONAL MODEL IN BOTH SCHOOLS}

In the case of AUIC-POLIMI, the educational Purposes seem to be centered: first, on the development of the design analysis and synthesis capacity - in fact, the importance attributed to both procedures in design studios is comparable; second, in the development of communicative and representative skills.

The educational Principles can be summarized as: first, design must necessarily be supported by an analytical information base - either from a context or from precedents; second, the way the design is communicatedpresented conditions the content, and therefore it must be a fundamental aspect of the architect's training; and third, the criterion for choosing and using the forms of representation is related to a particular objective or circumstance - there is no form of representation that stands out.

In terms of educational Practices: first, students have complete freedom in choosing and using forms of representation for design and critiques - despite the fact that professors use only sketching; second, students are encouraged to produce more structured representations (Purcell \& Gero, 1998) with a public or presentation character (Herbert, 1988); and third, the general tenor of design critiques is in favor of the continuity and improvement of the students' design ideas - then, through vertical moves (Goldschmidt, 1989).

In the case of FAUP, the educational Purposes seem to be centered: first, on the development of the design synthesis capacity as a fundamental aspect of the architect's training, supported by the perceptive-intuitive approach developed in other courses; second, in the development of a methodological sense of designing.

The educational Principles can be summarized as: first, the importance attached to personal sensitivity in design process - whether in recognition or transformation procedures; second, the way in which the design is communicated-represented is considered only from the point of view of clarity, disambiguation and rigor; and third, sketching or freehand drawing plays an essential role as a form of representation in design and in the general training of the architect.

In terms of educational Practices: first, students must use sketching as the main form of representation in design and in design critiques - in the same way as professors; second, students are encouraged to produce less structured representations (Purcell \& Gero, 1998) of a private or study nature (Herbert, 1988); and third, the general tenor of design critiques is in favor of exploring ideas - then, through horizontal moves (Goldschmidt, 1989). 


\section{CONCLUSION}

\subsection{FINAL NOTES}

It is possible to verify the importance of the representative component in the didactic approach to design - the Design Educational Model (DEM) - in both schools, despite the differences in its role. In AUIC-POLIMI model, representation is particularly relevant as a means of communication and presentation, whether the results of analysis or synthesis procedures. In the FAUP model, on the other hand, the main purpose of representation is to support the design process.

In AUIC-POLIMI model, the most structured forms of representation, associated with the analytical-synthetic approach to design, are valued. The criterion for choosing and using the forms of representation is based on a particular objective or circumstance. In the FAUP model, less structured forms of representation, associated with the intuitive-synthetic approach to design, are valued. Sketching is the main form of representation and a fundamental aspect of student training. It seems possible to conclude that the representative component is determinant and at the same time determines the DEM of both schools, integrating their educational Purposes, Principles and Practices.

It is expected that the knowledge base developed in this research may have three main contributions: to contribute to the maintenance of the educational model of AUICPOLIMI and FAUP; through the precise description of the methodological procedures, to contribute by transferability to similar studies; through the critical and objective framework of the problem underlying the forms of representation and its relation with architectural design teaching, to contribute to the broader discussion concerning the contemporary challenges on architectural education.

\subsection{STUDY LIMITATIONS}

A first limitation to be pointed out is related to the impossibility of having followed the design studios of the second semester at AUIC-POLIMI, for both the Bachelor and the Master Program. Although these attendances were foreseen in the initial work plan, the closure of the school due to the COVID-19 pandemic forced the early suspension of fieldwork. Moreover, the articulation of design studios with other courses in the curricular plan at AUIC-POLIMI, as in FAUP, needs verification. Finally, it would also be important to deepen the study of the individual work process of students in design studios beyond what happens during the design critiques.

\subsection{FUTURE WORK}

An important work to be developed in the near future is related to the recognition of the transformations and prevalence of design teaching - especially in the context of interactions between internal and external representations - when the direct personal relationship between professors and students is limited or prohibited. The COVID-19 pandemic implied an immediate adaptation of the ways of teaching and learning to the new circumstance, forcing the academy to resort to didactic models that have so far been little explored, especially in architectural education.

\section{REFERENCES}

Alves Costa, A. (1991). Páginas Brancas II. Porto: AEFAUP

Creswell, J. W. (1994). Research Design: Qualitative \& Quantitative Approaches. Thousand Oaks, Calif.: Sage Publications.

Dorta, T., Kinayoglu, G., \& Boudhraa, S. (2016). A new representational ecosystem for design teaching in the studio. Design Studies, 47, 164-186.

ESBAP. (1979). Regime de estudos : 79-80 : bases gerais / Escola Superior de Belas-Artes do Porto, Curso de Arquitectura. Porto: ESBAP.

Gero, J. S., \& Milovanovic, J. (2020). A framework for studying designthinking through measuringdesigners' minds, bodies and brains. Design Society, 6, 1-40.

Goldschmidt, G. (1989). Problem representation versus domain of solution in architectural design teaching. Journal of architectural and planning research, 204-215.

Goldschmidt, G. (1991). The Dialectics of Sketching. Creativity Research Journal, 4, 123-143.

Goldschmidt, G. (2014). Modeling the role of sketching in design idea generation. In A. Chakrabarti \& L. T. M. Blessing (Eds.), An Anthology of Theories and Models of Design (pp. 433-450). London: Springer-Verlag.

Goldschmidt, G. (2017). Manual sketching: Why is it still relevant? In S. Ammon \& R. Capdevila-Werning (Eds.), The Active Image: Architecture and Engineering in the Age of Modeling. Cham: Springer.

Hatch, J. A. (2002). Doing qualitative research in education settings. New York: State University of New York Press.

Have, R., \& Toorn, M. (2012). The role of hand drawing in basic design education in the digital age. Paper presented at the International Conference on Engineering and Mathemaatics, ENMA 2012.

Herbert, D. (1988). Study Drawings in Architectural Design: Their Properties as a Graphic Medium. Journal of Architectura Education, 41, 26-38.

Lyn, F., \& Dulaney, R. (2009). A case for drawing. ARCC Journal, $6(1), 23-30$

Manion, L., Cohen, L., \& Morrison, K. (1980). Research Methods in Education. London: Routledge.

Merriam, S. B. (1998). Qualitative Research and Case Study Applications in Education. San Francisco: Jossey-Bass.

Milovanovic, J. (2019). Exploration of architectural design studio pedagogy: Effect of representational ecosystems on design critiques. (PhD thesis). Loire Bretagne University.

Milovanovic, J., \& Gero, J. S. (2020). Modeling Design Studio Pedagogy: A Mentored Reflective Practice. Paper presented at the International Design Conference - Design 2020.

Nelson, G., \& Stolterman, E. (2012). The design way: Intentional change in an unpredictable world. London: MIT Press.

Oh, Y., Ishizaki, S., Gross, M. D., \& Yi-Luen Do, E. (2013). A theoretical framework of design critiquing in architecture studios. Design Studies, 34, 302-325.

Ortega y Gasset, J. (1983). Sobre el estudiar y el estudiante. In Obras Completas (pp. 545-554). Madrid: Alianza Editora.

POLIMI. (2019a). Regolamento Didattico del Corso di Studio in: Architectural Design and History - Progettazione Architettonica e Storia, Laurea Magistrale. In: Politecnico di Milano.

POLIMI. (2019b). Regolamento Didattico del Corso di Studio in: Progettazione dell'Architettura, Laurea Di Primo Livello. In: Politecnico di Milano.

Portas, N. (1986). Páginas Brancas. Porto: FAUP 
Purcell, A. T., \& Gero, J. S. (1998). Drawings and the design process. Design Studies, 19, 389-430.

Salkind, N. J. (2010). Encyclopedia of Research Design. London: SAGE Publications.

Schön, D. A. (1983). The reflective practioner: How professionals think in action. New York: Basic Books.

Schön, D. A. (1987). Educating the reflective Practitioner: Toward a new design for teaching and learning in the professions. San Francisco: Jossey-Bass Publishers.

Schön, D. A. (1992). Designing as reflective conversation with the materials of a design situation. Knowledge-Based Systems, 5(1), 3-14.

Self, J., \& Goldschmidt, G. (2018). Sketch Representation and Design as Generative Transformation. In P. Vermaas \& S. Vial (Eds.), Advancements in the Philosophy od Design. Cham: Springer.

Siza Vieira, Á. (2000). Imaginar a evidência. Lisbon: Edições 70.

Siza Vieira, Á. (2009). 01 textos. Porto: Civilização.

Stake, R. E. (1995). The art of case study research. Thousand Oaks: Sage Publications.

Távora, F. (1982). Da organização do espaço. Porto: ESBAP.
Távora, F. (1991). Intorno alla scuola di Porto. Casabella 579, 57.

Toorn, M. (2012). Notebooks as didactic tools in design education. Paper presented at the International Conference on Engineering and Mathematics, ENMA.

Toorn, M., \& Guney, A. (2011). Precedent analysis in landscape architecture: In search of an analytical framework. Paper presented at the IASDR2011: The 4th Conference on Design Research, Delft.

Tversky, B., \& Suwa, M. (2009). Thinking with sketches. In A Markman \& K. Wood (Eds.), Tools for Innovation. Oxford: Oxford Scholarship Online.

Visser, W. (2006). The cognitive artifacts of designing. New York: Lawrence Erlbaum Associates.

Williams, D.-O., \& Sanchez-Del-Valle, C. (2008). Overlaps, Boundaries and Continuities: Transforming Sketch. Paper presented at the Seeking the City: Visionaries on the Margins - Proceedings from the 96th ACSA.

Yin, R. K. (1984). Case Study Research. London: Sage Publications.

Yin, R. K. (2011). Qualitative Research from Start to Finish. London: The Guilford Press.Williams, J. H. (2008). Employee engagement: Improving anticipation in safety. Professional Safety, 53(12), 40-45. 